DOI $10.14746 / \mathrm{ssp} .2018 .2 .1$

\author{
Jędrzej Skrzypczak, Tadeusz Wallas
}

Uniwersytet im. Adama Mickiewicza w Poznaniu

\title{
Rola i wpływ mediów na postawy prosportowe młodzieży akademickiej
}

\begin{abstract}
Streszczenie: Kluczowym pytaniem badawczym w przypadku tego opracowania, była próba ustalenia czy media mogą mieć wpływ na postawy prozdrowotne, w szczególności sprzyjające podejmowaniu aktywności fizycznej, a nadto w jakich formach i na jakich płaszczyznach komunikacji medialnej należy skutecznie upowszechniać wzorce postępowania w zakresie promowania postaw prozdrowotnych, aby dotrzeć do grupy docelowej. Podjęta została próba określenia źródeł, z których studenci czerpią informacje na temat sportu, a także jak kształtują się ich zainteresowania dyscyplinami i wydarzeniami sportowymi, oczekiwania, gusta i preferencje związane z przekazami medialnych o tematyce sportowej, jak również postawy prozdrowotne. Badanie zostało przeprowadzone w 2017 r. poprzez ankietyzację studentów w wybranych ośrodkach akademickich. Uzyskano łącznie 489 ankiet, zawierających odpowiedzi studentów kilku polskich uczelni z różnych miast.
\end{abstract}

Słowa kluczowe: wpływ mediów, postawy prosportowe młodzieży akademickiej, media społecznościowe a sport

Q rodowisko studenckie w Polsce to obecnie populacja prawie 1,5 miliona młodych ludzi, w większości studiujących w dużych środowiskach miejskich. Z danych zaprezentowanych przez GUS według stanu na 30 listopada 2016 r. wynika, że ogółem na uczelniach publicznych i niepublicznych studiuje w Polsce 1348822 osoby w tym 776464 kobiet. Zdecydowana większość z nich to studenci studiów stacjonarnych (895 $725 \mathrm{w}$ tym 520672 kobiet), natomiast na studiach niestacjonarnych naukę pobiera ogółem 453097 osób, w tym 255792 kobiet (Dane wstępne, 2017).

Jednym z istotnych wskaźników oceny zdrowotności populacji jest tzw. wskaźnik samooceny zdrowia (SRH - ang. Self-rated Health), bowiem ,daje on obraz postrzegania różnych aspektów zdrowia fizycznego i psychospołecznego, zgodnie z definicją według Światowej Organizacji Zdrowia" (Mazur, 2015, s. 79). Wskazuje się w literaturze, iż samoocena 
swojego stanu zdrowia jest wśród młodzieży dużo lepsza niż wśród osób dorosłych (Mazur, 2015, s. 79; Woynarowska, Oblacińska, 2014, s. 45). $\mathrm{Z}$ badań przeprowadzonych przez CBOS wynika, że ankietowani w wieku od 18 do 34 lat w zdecydowanej większości, bo aż w 84\% oceniało swój stan zdrowia jako dobry, jako ,taki sobie” 14\%, a jako zły jedynie $1 \%$ ankietowanych. $\mathrm{Z}$ kolei $\mathrm{w}$ grupie powyżej 65 roku życia ta ocena, co w zasadzie nie może dziwić, jest całkowicie odwrotna. Mianowicie jedynie 19\% deklarowało, że ich stan zdrowia jest dobry, 56\% oceniało go jako „taki sobie”, a 35\% jako zły (CBOS, 2012, s. 3-4). Z pewnością styl życia w tym aktywność fizyczna jest jednym z czynników, które wpływają korzystnie na stan zdrowia (Romanowska-Tołłoczko, 2011, s. 90). Przy czym należy zaznaczyć, iż aktywność fizyczną definiuje się jako „każdą pracę wykonywaną przez mięśnie szkieletowe, charakteryzującą się ponadspoczynkowym wydatkiem energetycznym. Są to obciążenia fizyczne, którym organizm poddawany jest codziennie - podczas nauki, prac domowych, pracy zawodowej oraz w czasie wolnym. Może być ona spontaniczna, np. praca w ogrodzie, marsz do szkoły, zabawa lub odpowiednio zaplanowana pod względem obciążenia organizmu i celu zdrowotnego - ćwiczenia i trening" (Dzielska, Nałęcz, 2013, s. 32). Niniejsze opracowanie skupia się na tych ostatnich formach aktywności. Trzeba przyznać z jednej strony, że w całej populacji dorosłych Polaków obserwuje się korzystne zmiany związane $\mathrm{z}$ większą aktywnością ruchową. I tak z badań porównawczych pomiędzy 2007 a 2012 r. wynika, że liczba osób deklarujących, iż nawet okazjonalnie uprawiają sport (najczęściej wskazywano takie dyscypliny jak bieganie, pływanie, jazda na rowerze, gry zespołowe) wzrosła z $45 \%$ do $55 \%$, a osób uprawiających codziennie sport z $22 \%$ do $29 \%$. Z kolei w analizowanym okresie odnotowano, że grupa osób, którym nie zdarza się jakakolwiek aktywność nawet przez godzinę w tygodniu zmniejszyła się z 22\% do 17\%, przy czym odsetek tych, którzy deklarują taką aktywność codziennie wzrósł z 30\% do 37\%. O 5 punktów procentowych wzrosła według badań CBOS grupa osób, które regularnie, nie rzadziej niż raz w tygodniu uprawią gimnastykę, aerobik lub korzystają z siłowni (CBOS, 2012, s. 11-12). Z drugiej strony z dostępnych badań wynika, że nie więcej jak 10-15\% tej populacji posiada podstawową wiedzę na temat: własnej sprawności fizycznej, na temat atutów wynikających z aktywności fizycznej w różnych okresach ontogenetycznego rozwoju człowieka, posiada umiejętność ćwiczeń fizycznych i uprawiania prostych form wolnoczasowych w dorosłym życiu (Zalewska-Puchała, Majda, Korzonek, 2013, s. 506). Z przepro- 
wadzonych badań wynika, że w ostatniej dekadzie zaobserwowano co najmniej dwa niekorzystne zjawiska u dzieci i młodzieży, a mianowicie zwiększanie się masy ciała i wskaźnika BMI (ang. Body Mass Index), co należy wiązać z coraz częściej występującym zjawiskiem nadwagi i otyłości u dzieci i młodzieży, a nadto pogorszeniem sprawności fizycznej tej grupy populacji, co widoczne jest zwłaszcza w testach dotyczących gibkości, wytrzymałości i siły. Takie tendencje tłumaczy się zmniejszeniem aktywności fizycznej tej grupy wiekowej i coraz dłuższym czasem przebywania we względnym bezruchu, co z kolei wynika z coraz dłuższego czasu przeznaczonego na korzystanie z komputerów, smartfonów i telewizji (Woynarowska, Oblacińska, 2014, s. 44-45; Wolański, Dobosz, 2012, s. 8-44). Niewiele natomiast wiadomo na temat wpływu przekazów medialnych na zainteresowania, preferencje, a zwłaszcza postawy młodzieży akademickiej związane $\mathrm{z}$ uprawnianiem sportu i aktywnością fizyczną. Lukę informacyjną w tym zakresie należy uznać za poważany brak, wymagający uzupełnienia.

Problem jest tym istotniejszy, że media w ostatnich latach zmieniają się w sposób radykalny. Zwłaszcza narodziny Internetu sprawiły, że możemy mówić wręcz o rewolucji cyfrowej (Tapscott, 2010, s. 38-212). Technologie te skutkują m.in. zjawiskiem konwergencji mediów, ale jednocześnie dywergencji mediów. Konwergencja mediów to zjawisko połączenia odrębnych dotychczas sektorów takich jak: telekomunikacja, radiofonia i telewizja oraz technologie informatyczne (Goban-Klas, 2005, s. 47-162). W konsekwencji znikają dotychczasowe bariery odgradzające trzy odrębne do niedawna byty społeczne, ekonomiczne i prawne. Zjawisko dywergencji mediów oznacza, że dzięki możliwościom technologicznym te same treści (tzw. content) trafiają do odbiorców na różnych płaszczyznach odbioru, tzn. radiofonii i telewizji naziemnej, przekazów satelitarnych, kablowych, telefonii komórkowej lub innych urządzeń mobilnych albo internetu w tym tzw. social media. Jednym z efektów tych przeobrażeń, jest zjawisko zmiany form i platform konsumpcji mediów, zwłaszcza wśród młodych ludzi. Co nie mniej istotne, modyfikacji ulega także model komunikacji. Media cyfrowe charakteryzują się interaktywnością, a więc umożliwiają sytuację, kiedy każdy może przekazywać określone treści, stąd też można zaryzykować stwierdzenie, że każdy może stać się nadawcą. Po drugie, następuje indywidualizacja (personalizacja) przekazu, co polega na tym, iż każdy może otrzymywać treści w schemacie one-to-many, czy też w schemacie one-to-one. To oznacza, że w erze mediów cyfrowych możliwa jest personalizacja przekazu. Od- 
biorca może samodzielnie kształtować program, który otrzymuje. Wreszcie należy podkreślić, że media cyfrowe umożliwiają asynchroniczność komunikacji. Treść może być dostępna w miejscu i czasie swobodnie wybranym przez odbiorcę. Dlatego mówi się o mediach nielinearnych typu pull, w przeciwieństwie do mediów nazywanych linearnymi typu push (Rawolle, Hess, 2000, s. 89-98; Miczka, 2007, s. 186-187). Era cyfrowa charakteryzuje się nadto różnorodnością form świadczonych usług. Oprócz usług medialnych głównego nurtu, obserwuje się przekazy spersonalizowane, które są pewnym połączeniem usług linearnych i nielinearnych (Jung, 2005, s. 17-35; Kowalski, 2001, s. 22-31; Krzysztofek, 2007, s. 223-224).

Z dostępnych badań wynika niezbicie, iż zdrowie jest wartością najwyżej cenioną przez Polaków (Boguszewski, 2012; Puchalski, 2015, s. 261; Sasińska-Klas, 2015, s. 305 i n.). Z badań przeprowadzonych przez CBOS wynika, że zdrowie zajmuje drugie miejsce (74\%) w rankingu cenionych przez Polaków wartości, ustępując pierwszego miejsca jedynie szczęściu rodzinnemu $(84 \%)$. Ponadto, istnieje powszechne przekonanie, iż każdy ma właściwą i wystarczającą wiedzę o czynnikach wpływających na zdrowie, praktycznie każdy się zna (Sasińska-Klas, 2015, s. 260-261). Według innego badania z grudnia 2015 portale internetowe skupiające się na problematyce zdrowia i kondycji fizycznej odwiedzało ok. 9 mln użytkowników sieci (Polskie Badania Internetu, 2016). Istnieje jednak pilna potrzeba zbadania, jak media zwłaszcza te tzw. nowe media (Szpunar, 2008, s. 33), wpływają na podejmowanie szeroko rozumianej aktywności fizycznej i kształtowanie postaw prozdrowotnych.

Dziś nie ma wątpliwości, iż mariaż sportu i mediów nosi znamiona trwałego i nierozerwalnego związku. Relacje i transmisje z wydarzeń sportowych, zaspakajają potężne zainteresowanie wśród odbiorców, ale z drugiej zapewniają finansowanie sportowców i wydarzeń sportowych. Kontrakty na transmisje sportowe i możliwości relacjonowania największych imprez sportowych biją kolejne rekordy, podobnie zresztą jak wskaźniki popularności bohaterów tych wydarzeń. Nie dość, że zaliczani są do grona celebrytów, to ich status materialny także osiagga niebotyczny stan. Stąd też nie dziwi, iż dziś funkcjonują nie tylko odrębne rubryki sportowe, ale wręcz odrębne tytuły prasowe, czy też kanały relacjonujące przebieg wydarzeń sportowych (Beck, Bosshart, 2003, s. 6-14). Dotyczy to jednak przede wszystkim sportu zawodowego. Gorzej jest jednak, gdy chodzi o sport amatorski w tym akademicki. Zyskująjednak na znaczeniu audycje i programy o charakterze poradnikowym i tzw. lifestylowym. 
Stąd też pojawia się kluczowe pytanie badawcze, a mianowicie czy media mogą mieć wpływ na postawy prozdrowotne, w szczególności sprzyjające podejmowaniu aktywności fizycznej, a nadto w jakich formach i na jakich płaszczyznach komunikacji medialnej należy skutecznie upowszechniać wzorce postępowania w zakresie promowania postaw prozdrowotnych, aby dotrzeć do grupy docelowej. Podjęta została próba określenia źródeł, z których czerpią informacje na temat sportu, a także jak kształtują się ich zainteresowania dyscyplinami i wydarzeniami sportowymi, oczekiwania, gusta i preferencje związane z przekazami medialnymi o tematyce sportowej, jak również postawy prozdrowotne. Badanie zostało przeprowadzone w 2017 r. poprzez ankietyzację studentów w wybranych ośrodkach akademickich. Uzyskano łącznie 489 ankiet, zawierających odpowiedzi studentów kilku polskich uczelni z różnych miast. Należy tu wskazać, iż poddano badaniu studentów Uniwersytetu Marii Curie-Skłodowskiej w Lublinie, Uniwersytetu Przyrodniczego w Poznaniu, Uniwersytetu Rzeszowskiego, Uniwersytetu Mikołaja Kopernika w Toruniu, Uniwersytetu Warszawskiego, Uniwersytetu Śląskiego w Katowicach. Spośród ankietowanych, większość bo 348 ankiet wypełniły kobiety (71\%), a mężczyźni łącznie 140 (tj. 29\% ogółu). Dla porządku należy odnotować, że jedna osoba nie udzieliła jakiekolwiek odpowiedzi. Ankiety przeprowadzono w zasadniczej mierze pośród studentów uczestniczących w zajęciach wychowania fizycznego. Wyjątkiem był Uniwersytet Warszawski, gdzie badanie przeprowadzono pośród studentów Wydziału Dziennikarstwa, Informacji i Bibliologii. Większość badanych to studenci 1 roku (łącznie 401 osób), studentów roku II było 42 osoby, III roku - 14, IV roku - 26, a 5 roku - 5 osób (jak już wspomniano, jedna osoba nie udzieliła żadnej odpowiedzi).

Pierwsze z pytań dotyczyło samooceny kondycji fizycznej badanych. Pytanie było tak skonstruowane, że można było udzielić odpowiedzi w przedziale od 1 do 5, gdzie wskazanie 1 oznaczało negatywną ocenę, a 5 idealną. Jak już wyżej wskazano z badań przeprowadzonych przez CBOS wynika, że ankietowani w wieku od 18 do 34 lat w zdecydowanej większości, bo aż w 84\% oceniało swój stan zdrowia jako dobry, jako „taki sobie" $14 \%$ a jako zły jedynie $1 \%$ ankietowanych. W naszych badaniach wnioski nie są aż tak optymistyczne. Wprawdzie skala była bardziej rozbudowana (5 stopni, a w badaniu CBOS 3), to najwięcej bo aż $50 \%$ (243 osób) oceniło swój stan na 3. Ocenę 4 i 5 wskazało odpowiednio $28 \%$ badanych (135 osób) i tylko 2\% (8 osób). Negatywnie swoją kondycję fizyczną oceniło 3\%. 
Kolejne pytanie dotyczyło tego, czy ankietowani uprawiają sport, a jeżeli tak to czy amatorsko, czy zawodowo. Do amatorskiego uprawiania sportu przyznało się 59\% respondentów, zawodowo 4\%, natomiast $35 \%$ podało, że w ogóle nie uprawia. Jest to o tyle zaskakujące, że przecież większość była poproszona o wypełnienia ankiety podczas akademickich zajęć z wychowania fizycznego. W przypadku tego pytania $1 \%$ badanych nie udzieliło odpowiedzi.

Następne pytanie dotyczyło kwestii jak często ankietowani podejmują aktywność fizyczną w ciagu tygodnia. Odpowiedzi, iż codziennie udzieliło tylko $2 \%$ ankietowanych, do aktywności kilka razy w tygodniu przyznało się $37 \%$, a raz w tygodniu zadeklarowało $32 \%$ badanych. Co może budzić zdziwienie 29\% osób, nie udzieliło jakiejkolwiek odpowiedzi na takie pytanie.

Kolejne pytanie dotyczyło tego jaki rodzaj sportu wybierają badani studenci. I znowu aż 182 osób nie udzieliło odpowiedzi, natomiast pośród najpopularniejszych sportów wskazano bieganie (59 osób), ćwiczenia na siłowni 50 osób, uprawianie siatkówki deklarowało 29 osób, do piłki nożnej przyznały się 26 osoby, pływanie uprawiały 23 osoby, fitness i gimnastykę 19 osób, jazdę na rowerze 15 osób, taniec 14 osób, tenis 14 osób, koszykówkę 12 osób, aerobik wskazało 7 osób a zumbę 5. Z kolei uprawianie jazdy konnej deklarowały 3 osoby, lekką atletykę 2 osoby, badminton 1 osoba, podobnie jak hokej i kalistenikę (czyli trening siłowy oparty o ćwiczenia z wykorzystaniem własnej masy ciała).

W kolejnym pytaniu próbowano ustalić jakie motywacje decyduja o podejmowaniu aktywności fizycznej i uprawiania sportu. Zdecydowana większość bo aż 277 respondentów podało, że robi to dla zdrowia, niewiele mniej bo 207 osób wskazało, iż robi to żeby czuć się atrakcyjnie, tylko 15 osób udzieliło odpowiedzi, „bo to modne”, a tylko 7 osób stwierdziło, że podejmuje taką aktywność zachęcona przez przekazy medialne.

Następnie zapytano o to kto lub co zachęca najskuteczniej do uprawiania sportu. Największą grupę bo $29 \%$ osób stanowią ci, którzy są motywowani przez znajomych, tylko nieco mniej bo $22 \%$ ankietowanych odpowiedziało, że nikt ani nic nie zachęca, na rodzinę jako motywatora wskazało $10 \%$ respondentów. Tylko dla 5\% badanych to sukcesy polskich sportowców były inspiracją do podejmowania aktywności. Dla 3\% osób przykład płynący od celebrytów był inspiracją do podjęcia takich działań. W tym przypadku, $4 \%$ respondentów podało, że to inne niż wymienione powyżej osoby, podmioty czy instytucje zachęcały ich do takiego kroku. Niestety aż $27 \%$ osób nie udzieliło żadnej odpowiedzi. 
Po tych pytaniach, nastąpiły kolejne, które odnosiły się bezpośrednio do analizy wpływu mediów na podejmowanie aktywności fizycznej badanych, a w szczególności, które z mediów najskuteczniej zachęcają do uprawiania sportu? Zdecydowanie przodują w tym zakresie nowe media. Na media społecznościowe wskazało aż 201 osób, strony www wymieniło 157 osób, telewizję podało tylko 80 osób, prasę 19 osób, radio 11 osób, a inne media 37 osób. Takie wyniki i odpowiedzi na to pytanie były o tyle do przewidzenia, bowiem to pokazuje doskonale jak przedstawia się rozkład wśród młodzieży konsumpcji mediów. Z pewnością dominują internet i media społecznościowe (choć te to także internet). $Z$ badań przeprowadzonych przez PBI/Gemius w grudniu 2012 r. wynikało, że było ok. 13 mln użytkowników FB i $8 \mathrm{mln}$ portalu NK, w tym $40 \%$ to osoby poniżej 24 roku życia (Makaruk, 2013, s. 69).

Kolejne pytanie dotyczyło tego czy audycje medialne o sporcie (w tym akademickim) i sukcesy rówieśników, sprawiają że chętniej podejmują aktywność sportową. Wyniki tego pytania nie są jednoznaczne. Mianowicie $20 \%$ ankietowanych udzieliło odpowiedzi twierdzacej, ale $25 \%$ przeczącej, a $28 \%$ ankietowanych było niezdecydowanych. Tyle samo tj. aż $28 \%$ nie udzieliło odpowiedzi.

W dalszej kolejności zapytano wskazaną wyżej grupę studentów jaki typ treści medialnych zachęca badanych do uprawiania sportu? Zdecydowanie najwięcej bo aż 144 osoby wskazało transmisje/relacje sportowe, 93 osoby twierdziło, że są to różnego rodzaju poradniki, a na audycje lifestylowe wskazało 75 osób. Niewiele mniej bo 72 osoby podały, iż są to inne typy przekazów medialnych.

Kolejne pytanie dotyczyło tego czego ankietowani oczekują od poradników dotyczących sportu i aktywności fizycznej. I tak w 323 przypadkach podano, że oczekuje treści dla początkujących i zaawansowanych adeptów sportu, w 262 przypadkach stwierdzono, że poszukuje się informacji na temat diet i sposobów właściwego, odpowiedniego i zdrowego odżywiania, w 92 przypadkach podano, że informacji o przeciwwskazaniach zdrowotnych w uprawianiu dyscyplin sportowych, 77 odpowiedzi dotyczyło oczekiwań co do informacji o przepisach i zasadach dyscypliny, 72 odpowiedzi dotyczyło oczekiwań co do informacji o sprzęcie sportowym, 42 odpowiedzi wskazywało na oczekiwania w zakresie informacji o najlepszych sportowcach, 18 wskazań dotyczyło informacji o historii danej dyscypliny.

W ankiecie zapytano także jakie dyscypliny sportowe śledzą ankietowani w przekazach medialnych. Z pewnością nie może dziwić, że piłka 
nożna zajęła pierwsze miejsce (236 odpowiedzi), siatkówka 181 wskazań, koszykówka 39, inną dyscyplinę podało 115 osób. Natomiast 106 osób podało, że nie interesuje się żadną dyscypliną sportową.

Następne pytanie dotyczyło źródeł wiedzy o sporcie. Na pytanie skąd czerpiesz informacje o sporcie, aż 383 osób wskazało internet, na drugim miejscu bo 199 osób wskazało telewizję, media społecznościowe zajęły trzecie miejsce (195 wskazań), prasę 55, radio 36, a inne źródła 56 odpowiedzi. 23 osoby odpowiedziało, że nie poszukuje takich informacji, a to dlatego, że ta problematyka nie interesuje ich. Przy tej okazji zapytano grupę badawczą, ile godzin dziennie ogląda telewizję. W odpowiedzi $36 \%$ podało, że nie ogląda TV, dokładnie tyle samo ankietowanych podało, że mniej niż $1 \mathrm{~h}$ dziennie, do $2-4 \mathrm{~h}$ przyznało się $24 \%$ pytanych, a powyżej $4 \mathrm{~h}$ spędza przed telewizorem tylko $1 \%$ respondentów. $2 \%$ badanych nie zaznaczyło żadnej odpowiedzi. Na podobne pytanie dotyczące długości dziennego korzystania z radia 39\% podało, że w ogóle nie słucha, mniej niż 1 godzinę korzysta $\mathrm{z}$ tego medium $38 \%, 2-4 \mathrm{~h}$ spędzania w towarzystwie radia zadeklarowało $16 \%$ pytanych, powyżej 4 h tylko $4 \%$, a $3 \%$ nie odpowiedziało $\mathrm{w}$ ogóle na to pytanie. $\mathrm{Z}$ kolei na pytanie ile godzin dziennie korzystasz z internetu, odpowiedzi w ogóle udzieliło mniej niż $1 \%$ badanych, do $1 \mathrm{~h} 11 \%$, przedział $2-4 \mathrm{~h}$ zadeklarowało $51 \%$ pytanych, powyżej $4 \mathrm{~h}$ aż 35\%. 2\% ankietowanych nie udzieliło odpowiedzi w tym przypadku. W przypadku pytania ile godzin dziennie korzystasz z mediów społecznościowych 4\% badanych podało, że w ogóle, do $1 \mathrm{~h}$ korzysta $30 \%$, w przedziale $2-4 \mathrm{~h}$ deklarowało $43 \%$ pytanych, a powyżej 4 h wskazało $20 \%$ odpowiadających. 14 osób tj. 3\% nie udzieliło odpowiedzi.

Na koniec zapytano, o źródła pozyskiwania przez badanych informacji na temat sportu z mediów akademickich lub kierowanych do studentów? Dla 16\% badanych były to strony internetowe lub profile FB AZS lub uczelni. $67 \%$ ankietowanych podało, że nie uzyskuje takich informacji, a $15 \%$ nie potrafiło udzielić odpowiedzi. $2 \%$ badanych nie udzieliło odpowiedzi.

Jak widać, dynamicznie zmieniają się formy konsumpcji mediów przez młodzież, w tym przypadku akademicką, $\mathrm{z}$ tradycyjnych przekazów w stronę nowych mediów. Choć ankietowani deklarowali, że media w tym nowe media nie mają większego wpływu na ich postawy i aktywność fizyczną, to jednak wydaje się, że te odpowiedzi, nie są do końca wiarygodne. Wskazują chociażby na to pytania o rolę znajomych i przyjaciół jako najpoważniejszych motywatorów do podejmowania takiej ak- 
tywności. A przecież kontakt pomiędzy tymi osobami odbywa się najczęściej za pomocą FB, Twittera itd. Z pewnością też korzystanie z tych mediów, zajmujące coraz więcej dziennego czasu, stanowi konkurencję dla aktywności fizycznej. Wystarczy tylko przytoczyć, że w niektórych miastach instaluje się sygnalizację świetlną w krawężnikach, aby zapewnić bezpieczne przejście przez ulicę, bez odrywania wzroku od smartfona. Z pewnością, aby dotrzeć z właściwym przekazem do grupy docelowej, konieczne jest uwzględnienie specyfiki nowych mediów i zjawiska dywergencji mediów.

\section{Bibliografia}

Beck D., Bosshart L. (2003), Sports and Media, „Communication Research Trends”, vol. 22, nr 4.

Bissel K., Perry S. D. (red.) (2015), The Olimpics, Media and Society, London-New York.

Boguszewski R. (2012), Polacy o swoim zdrowiu oraz prozdrowotnych zachowaniach $i$ aktywnościach, Warszawa 2012, http: //www.cbos.pl/SPISKOM.POL/2012/K_110_12.PDF, 5.09.2017.

CBOS (2012), Komunikat z badań, BS/110/2012, Polacy o swoim zdrowiu oraz prozdrowotnych zachowaniach $i$ aktywnościach, Warszawa.

Dane wstępne (2017) dotyczące szkolnictwa wyższego w roku akademickim 2016/2017 - stan w dniu 30.11.2016 r., GUS, http://stat.gov.pl/obszary-tematyczne/edukacja/edukacja/szkolnictwo-wyzsze-w-roku-akademickim20162017-dane-wstepne, 8,4.html, 12.02.2018.

Dzielska A., Nałęcz H. (2013), Aktywność fizyczna młodzieży i jakość życia zwiazana ze zdrowiem, w: Zdrowie dzieci i młodzieży w wymiarze socjomedycznym, red. J. Szymborski, W. Zatoński, Warszawa.

Fidler R. F. (1997), Mediamorphosis: Understanding New Media, Thousand OaksLondon.

Goban-Klas T. (2005), Cywilizacja medialna, Warszawa.

Goban-Klas T. (2007), Radiomorphosis cultural and technological aspects of radio development, w: The Medium with Promising Future. Radio in Central and Eastern European Countries, Lublin, red. S. Jędrzejewski, s. 13-20.

Hutchins B., Rowe D. (red.) (2016), Digital media Sport. Technology, Power and Culture in the Network Society, London-New York.

Jung B. (2005), Nowe technologie w mediach elektronicznych. Cyfryzacja, Internet i co dalej?, „Studia Medioznawcze”, nr 3, s. 17-35.

Konopczyński M. (red.) (2016), NASK. Nastolatki 3.0. Wybrane wyniki ogólnopolskiego badania uczniów w szkolach, Warszawa. 
Kowalski T. (2001), Mediamorfoza - rzecz o przyszłości mediów i mediach przyszłości $w$ aspekcie konwergencji, ,Studia Medioznawcze”, nr 1, s. 22-31.

Krzysztofek K. (2007), Status mediów cyfrowych: stare i nowe paradygmaty, w: Studia nad komunikacja popularna, międzykulturowa, sieciowa i edukacyjna, red. J. Fras, Torun.

Lefever K. (2012), New Media and Sport. International Legal Aspects, The Hague.

Makaruk K. (2013), Korzystanie z portali społecznościowych przez młodzież, Wyniki badania EU NET.

Mazur J. (red.) (2015), Zdrowie i zachowania zdrowotne młodzieży szkolnej na tle wybranych uwarunkowań socjodemograficznych, Warszawa.

Miczka T. (2007), Nowe media jako nowe formy komunikowania politycznego i nowe formy ,,dyscyplinujacej technologii władzy”, w: Media w Polsce. Pierwsza władza IV RP, red. M. Sokołowski, Warszawa.

Negroponte N. (1997), Cyfrowe życie. Jak się odnaleźć w świecie komputerów, Warszawa.

Polskie Badania Internetu (2016), Internetowe serwisy o zdrowiu, Zawartość i popularność serwisów, profil użytkowników, Warszawa, http://pbi.org.pl/wp-content/ uploads/2017/02/2016_10_RAPORT-Internetowe-serwisy-o-zdrowiu-2016. pdf, 7.09.2017.

Puchalski K. (2015), Potoczne myślenie o zdrowiu i chorobie, „Zeszyty Prasoznawcze", $\mathrm{nr} 2$.

Rask K., Astedt-Kurki P., Laippala P. (2002), Adolescent subjective well-being and realized values, „Journal of Advanced Nursing”, May, nr 38(3).

Rawolle J., Hess T. (2000), New Digital Media and Devices. An Analysis for the Media Industry, „The International Journal on Media Management”, vol. 2, nr II.

Romanowska-Tołłoczko A. (2011), Styl życia studentów oceniany w kontekście zachowań zdrowotnych, „Hygeia Public Health”, nr 46 (1).

Sasińska-Klas T. (2015), Zdrowie i opieka zdrowotna w odbiorze społecznym (w świetle badań opinii publicznej w Polsce w latach 2009-2014), „Zeszyty Prasoznawcze", nr 2.

Szpunar M. (2008), Czym sq nowe media - próba konceptualizacji, „Studia Medioznawcze", nr 4.

Szredzińska R. (2017), Zdrowie dzieci i młodzieży, Warszawa.

Tapscott D. (2010), Cyfrowa dorostość. Jak pokolenie sieci zmienia nasz świat, Warszawa.

Veltman K. H. (2006), Understanding New Media. Augmented Knowledge\&Culture, Calgary.

Whitehead J., Telfer H., Lambert J. (red.) (2015), Values in Youth SPort and Physical Education, London-New York.

Wolański N., Dobosz J. ( 2012), Tendencje przemian motoryczności człowieka (międzydekadowe zmiany efektywności), w: Uwarunkowania rozwoju dzieci i młodzieży wiejskiej, red. A. Wilczewski, Biała Podlaska. 
Woynarowska B., Oblacińska A. (2014), Stan zdrowia dzieci i młodzieży. Najważniejsze problemy zdrowotne, w: Zdrowie dzieci i młodzieży. Wybrane zagadnienia, red. J. Szymczak, Studia Biura Analiz Sejmowych nr 2 (38).

Zalewska-Puchała J., Majda A., Korzonek R. (2013), Zachowania zdrowotne i poczucie własnej skuteczności studentów w utrzymaniu zdrowia, „Problemy Pielęgniarstwa", nr 21 (4).

\section{The role and influence of the media on the attitude of students to sports}

\section{Summary}

The key research question in this paper was an attempt to determine whether the media can have influence on health attitudes, in particular encouraging physical activity or practicing sports, and what forms and levels of communication via the media should be used to ensure effective promotion of pro-health attitudes among students. An attempt was made to identify the sources from which students get information about sports, as well as to determine their interest in sport disciplines and events, expectations and preferences related to sports media coverage, as well as pro-health attitudes. The study was conducted in 2017 , by surveying students in selected academic centers. A total of 489 questionnaires were received, containing the answers of students from several Polish universities in different cities.

Key words: media influence, sports activities, pro-sports attitudes, social media and sport

Data przekazania tekstu: 3.04.2018; data zaakceptowania tekstu: 24.04.2018. 
